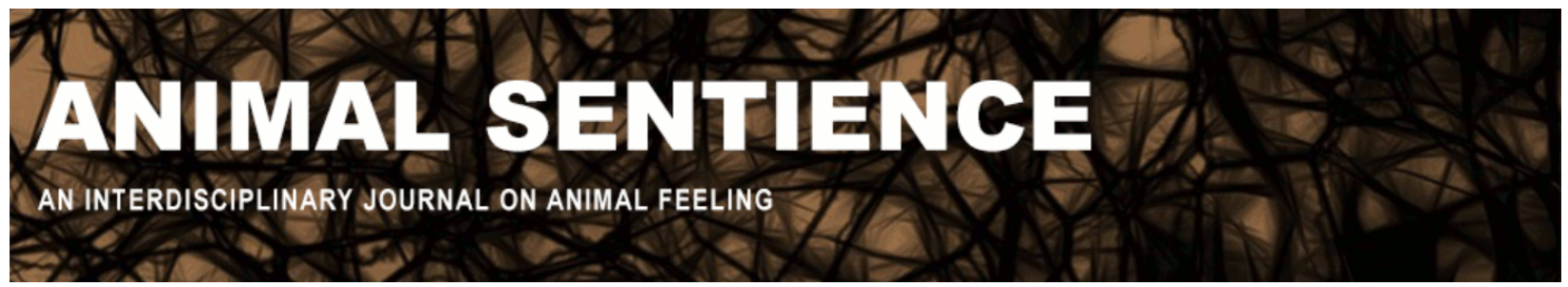

Wienhues, Anna (2020) Disentangling different forms of justice. Animal Sentience $27(21)$

DOI: $10.51291 / 2377-7478.1554$

Date of submission: 2020-02-07

Date of acceptance: 2020-02-20

(c)

This article has appeared in the journal Animal

Sentience, a peer-reviewed journal on animal

cognition and feeling. It has been made open access,

free for all, by WellBeing International and deposited

in the WBI Studies Repository. For more information,

please contact

wbisr-info@wellbeingintl.org.

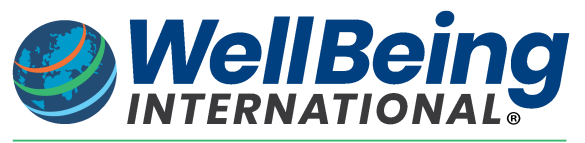

SOLUTIONS FOR PEOPLE, ANIMALS AND ENVIRONMENT 


\title{
Disentangling different forms of justice
}

Commentary on Treves et al. on Just Preservation

\author{
Anna Wienhues \\ Center for Ethics \\ University of Zurich
}

\begin{abstract}
Treves et al.'s article is an important contribution to an emerging interdisciplinary literature on what constitutes a viable and just response to the current biodiversity crisis. My commentary addresses three interrelated themes: (1) overcoming divisions, (2) hierarchies of moral worth and (3) 'multispecies justice' in the broader context of justice.
\end{abstract}

\begin{abstract}
Anna Wienhues, postdoctoral researcher in environmental philosophy, Center for Ethics and the University Research Priority Program on Global Change and Biodiversity, University of Zurich, Switzerland. Her research focus is environmental ethics and political philosophy. Website
\end{abstract}

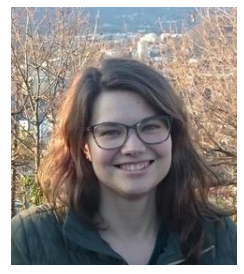

Treves et al. (2019a,b) seek a viable and just response to the current biodiversity crisis. They claim that conservation biology is working with an 'inadequate, muddled ethic' (2019a, p. 134); their article is meant to address this shortcoming. I am particularly interested in the sub-question about what constitutes a just response to this crisis and agree that justice can and should be extended to nonhuman living beings. However, I do not agree with all the claims made by the authors and would like to comment briefly on the following three themes.

1. Overcoming Divisions. Strategically, I am not sure how useful it is to describe accounts that are non-anthropocentric as speciesist (as implied by the authors' discussion of Vucetich et al. 2018). Some non-anthropocentric ethical positions are clearly more inclusive and 'radical' than others, but the less inclusive and more hierarchical perspectives should still be accepted pragmatically as part of a broader alliance for a world that is more just. Because of the complex entanglement of injustices towards humans and nonhumans, addressing injustices will require careful compromises (Wienhues 2018). Acknowledging the injustices done to nonhuman beings does not require downplaying the serious injustices faced by many humans, as Treves et al. also acknowledge. The importance of human wellbeing need not rest on claims of human superiority. The purpose of asserting that human wellbeing is not negotiable (which Treves et al. call into question in their discussion of Vucetich et al.) may be so as to (rightly) protect already marginalized human communities rather than to accord priority to the 'luxury' needs of the wealthy.

2. Hierarchies of Moral Worth. Egalitarian accounts of moral standing that accord exactly the same moral worth to nonhumans and humans are not the only alternative to hierarchical 
accounts that accord more moral worth to humans. A third alternative is that moral worth is actually incommensurable. This alternative is neither egalitarian nor hierarchical; and in developing a theory of interspecies justice, this option is preferable because it gives more conceptual space to a contextual and relational assessment of the problem - something that seems to interest Treves et al. too.

3. Multispecies Justice. Treves et al. are right that justice has an inbuilt individualism. A lot of conceptual confusion comes from overstretching the notion of justice and obscuring its distinctness from morality in general. Accounts of justice to nonhumans are important but cannot answer all questions in environmental ethics. Treves et al. should make these differences more explicit. Justice to nonhumans should be based on a political biocentrism that includes all living beings. This is as inclusive as possible within the boundaries of what the notion of justice can cover. It is 'political' insofar as it can cover issues such as fair distribution and participation, but without aiming to provide a broader environmental ethic.

Having moral considerability or intrinsic moral value is not enough to be a recipient of justice. (This contrasts with commentator Washington's 2019 view that ecosystems have greater standing in the context of justice.) Ecosystems might have moral value but we should not overstretch the concept of justice. People have many good reasons for ambitious biological conservation agendas but not all of these fit into the justice mold. This limits how inclusive an account of interspecies justice can be. Many theorists would be even more restrictive than the account I am proposing. Most moral philosophers (and readers of this journal, as exemplified by Paez's 2020 commentary) would disagree with me that all living (rather than just sentient) beings can be accorded moral standing, which is a necessary (but not sufficient) condition for being a recipient of justice.

Treves et al. use the term 'multispecies' justice. This is a useful umbrella term, but 'green' justice towards humans (i.e., environmental justice) and towards nonhumans (i.e., 'interspecies/ecological justice') need to be kept distinct. I use interspecies and ecological justice interchangeably because the latter has also been used by biocentric theorists (Baxter 2005); but this is more a question of a label preference. The crucial point is that there are important differences between these two spheres of green justice. These are somewhat obscured if too much emphasis is put on what Treves et al. (2019a) call a 'multispecies society' (p. 138). This is not a way of setting humans apart from nature, because both are accounts of justice in nature. However, because the relationships that ground these communities differ in several important respects (as Attfield 2019 indicates in his commentary), what justice demands is diverse too. The possibility of conflicts among these demands (as noted in the commentary by Palmer \& Fischer 2019) is a further complication because we also need to distinguish between different communities of interspecies justice (e.g., justice toward 'wild' beings, companion animals, etc.). This becomes clearer when we distinguish the 'moral community' at large from more specific communities of justice. A dual account of environmental and interspecies justice can put these two domains of justice into conversation. Using a common theoretical language, we can point out, on the one hand, instances where environmental and interspecies justice can support each other, and on the other hand, cases of conflicting interests and needs that are unavoidable in the current context of entangled injustices. (For more on points 2 and 3, see Wienhues 2020.) 


\section{References}

Attfield, R. (2019) Futurity, selves and further organisms. Animal Sentience 27(4).

Baxter, B. (2005) A Theory of Ecological Justice. Taylor and Francis e-library.

Paez, E. (2020) Preserving nature for the benefit of all sentient individuals. Animal Sentience $27(18)$.

Palmer, C. and Fischer, B. (2019) Just policy paralysis? Animal Sentience 27(3).

Treves, A., Santiago-Ávila, F. J. and Lynn, W. S. (2019a) Just preservation. Biological Conservation 229: 134-141.

Treves, A., Santiago-Ávila, F. J. and Lynn, W. S. (2019b) Just preservation. Animal Sentience 27(1).

Vucetich, J. A., Burnham, D., Macdonald, E. A., Bruskotter, J. T., Marchini, S., Zimmermann, A. and Macdonald, D. W. (2018) Just conservation: What is it and should we pursue it? Biological Conservation 221: 23-33.

Washington, H. (2019) Justice for nature. Animal Sentience 27(2).

Wienhues, A. (2018) Situating the half-earth proposal in distributive justice: Conditions for just conservation. Biological Conservation 228: 44-51.

Wienhues, A. (2020) Ecological Justice and the Extinction Crisis: Giving Living Beings Their Due. Bristol University Press. 


\section{Call for Papers}

Special Issue of the Journal of Consciousness Studies

Plant Sentience: Theoretical and Empirical Issues

Guest Editors: Vicente Raja (Rotman Institute of Philosophy, Western University)

Miguel Segundo-Ortin (School of Liberal Arts, University of Wollongong)

In this special issue, we address the issue of plant sentience/consciousness from different disciplines that combine both theoretical and empirical perspectives. Some of the questions to be addressed in the special issue include the following:

- Plants exhibit interesting behaviors; does this entail that they are conscious to some extent?

- What are the requirements for a living organism to be conscious? Do plants meet these requirements?

- What does the possibility of plant sentience/consciousness entail for the study of the evolution of consciousness?

- Is it just a categorical mistake to attribute consciousness to plants?

- Can we talk about different levels or degrees of consciousness?

\section{How to submit?}

Deadline: June 1 $\mathbf{1}^{\text {st }}, \mathbf{2 0 2 0}$

Please submit your papers (max. 9000 words including footnotes, references, abstract, etc.) to vgalian@uwo.ca with subject "Paper Special Issue JCS".

For more information, including bibliography and more detailed descriptions of the topics and questions to be addressed in the papers submitted to the special issue, please contact the guest editors at vgalian@uwo.ca (Vicente) or ms0693@uowmail.edu.au (Miguel). 